\title{
Indigenous arthropod natural enemies of the invasive brown marmorated stink bug in North America and Europe
}

\author{
Paul K. Abram ${ }^{1} \cdot$ Kim A. Hoelmer ${ }^{2}$ Angelita Acebes-Doria ${ }^{3} \cdot$ Heather Andrews $^{4}$. \\ Elizabeth H. Beers ${ }^{5} \cdot$ J. Christopher Bergh ${ }^{3} \cdot$ Ric Bessin $^{6} \cdot$ David Biddinger $^{7}$. \\ Paul Botch $^{8}$ - Matthew L. Buffington ${ }^{9} \cdot$ Mary L. Cornelius ${ }^{10}$ - Elena Costi ${ }^{11}$. \\ Ernest S. Delfosse $^{8} \cdot$ Christine Dieckhoff $^{12} \cdot$ Rachelyn Dobson $^{6} \cdot$ Zachary Donais $^{13}$. \\ Matthew Grieshop $^{8}$ - George Hamilton ${ }^{14}$ - Tim Haye ${ }^{15}$ - Christopher Hedstrom ${ }^{16}$. \\ Megan V. Herlihy ${ }^{10}$ • Mark S. Hoddle ${ }^{17}$ - Cerruti R. R. Hooks ${ }^{18}$ - Peter Jentsch ${ }^{19}$. \\ Neelendra K. Joshi' ${ }^{20}$. Thomas P. Kuhar ${ }^{21}$. Jesus Lara' ${ }^{17}$ Jana C. Lee ${ }^{22}$. \\ Ana Legrand ${ }^{13} \cdot$ Tracy C. Leskey $^{23} \cdot$ David Lowenstein $^{4} \cdot$ Lara Maistrello $^{11}$. \\ Clarissa R. Mathews ${ }^{24}$ • Joshua M. Milnes ${ }^{5}$ - William R. Morrison III $^{25}$. \\ Anne L. Nielsen ${ }^{26}$ - Emily C. Ogburn ${ }^{27}$ - Charles H. Pickett ${ }^{28}$ - Kristin Poley ${ }^{8}$. \\ John Pote $^{26}$ - James Radl ${ }^{29}$ - Paula M. Shrewsbury ${ }^{18}$ - Elijah Talamas9,30 . \\ Luciana Tavella $^{31} \cdot$ James F. Walgenbach $^{27} \cdot$ Rebeccah Waterworth ${ }^{18}$. \\ Donald C. Weber ${ }^{10} \cdot$ Celeste Welty $^{29} \cdot$ Nik G. Wiman ${ }^{4}$
}

Received: 4 April 2017/Revised: 22 May 2017/Accepted: 30 May 2017/Published online: 8 June 2017 (C) Her Majesty the Queen in Right of Canada 2017

Abstract Since the establishment of the brown marmorated stink bug, Halyomorpha halys (Stål) (Hemiptera:

Communicated by M. Traugott.

Special Issue: The brown marmorated stink bug Halyomorpha halys an emerging pest of global concern.

Electronic supplementary material The online version of this article (doi:10.1007/s10340-017-0891-7) contains supplementary material, which is available to authorized users.

Paul K. Abram

paul.abram@canada.ca

1 Agriculture and Agri-Food Canada, Agassiz Research and Development Centre, Agassiz, BC, Canada

2 Beneficial Insects Introduction Research Unit, USDA Agricultural Research Service, Newark, DE, USA

3 Alson H. Smith Jr. Agricultural Research and Extension Center, Virginia Tech, Winchester, VA, USA

4 Department of Horticulture, Oregon State University, Corvallis, OR, USA

5 Washington State University, Tree Fruit \& Extension Center, Wenatchee, WA, USA

6 Department of Entomology, University of Kentucky, Lexington, KY, USA

7 Pennsylvania State University, Fruit Research \& Extension Center, Biglerville, PA, USA
Pentatomidae) in North America and Europe, there has been a large, multi-group effort to characterize the composition and impact of the indigenous community of arthropod natural enemies attacking this invasive pest. In this review, we combine 98 indigenous natural enemy datasets spanning a variety of sampling methods, habitats, and geographic areas. To date, the vast majority of $H$. halys biological control research has focused on the egg stage, using sentinel egg masses to characterize indigenous

8 Department of Entomology, Michigan State University, East Lansing, MI, USA

9 Systematic Entomology Laboratory, USDA Agricultural Research Service, Washington, DC, USA

10 Invasive Insect Biocontrol and Behavior Laboratory, USDA Agricultural Research Service, Beltsville, MD, USA

11 Department of Life Sciences, University of Modena and Reggio Emilia, Modena, Italy

12 Department of Entomology and Wildlife Ecology, University of Delaware, Newark, DE, USA

13 Department of Plant Science and Landscape Architecture, University of Connecticut, Storrs, CT, USA

14 Department of Entomology, Rutgers University, New Brunswick, NJ, USA

15 CABI, Delémont, Switzerland 
parasitoid and predator communities and their contribution to $H$. halys egg mortality. Although egg parasitism and predation levels by indigenous natural enemies are low (typically $<10 \%$ each) in most surveys, total egg mortality attributable to natural enemies can be higher (typically between 5 and $25 \%$; up to $83 \%$ ) —even though these values were likely underestimated in most cases because some mortality due to biological control was not recognized. In North America, where the most data are available, it appears that the relative prevalence of different indigenous parasitoid species varies among habitat types, particularly between crop and non-crop habitats. Predator species responsible for egg mortality are much less commonly identified, but appear to include a wide variety of generalist chewing and sucking predators. To date, studies of natural enemies attacking $H$. halys nymphs and adults are relatively rare. Based on our review, we identify a number of key research gaps and suggest several directions for future research.

Keywords Invasive species - Biological control ·

Parasitoids · Predators $\cdot$ Pentatomidae $\cdot$ Halyomorpha halys

\section{Key message}

- The identity and impact of arthropod parasitoids and predators attacking the invasive crop pest Halyomorpha halys in recently invaded areas are reviewed.

- Impact of indigenous biological control agents on $H$. halys is usually quite low, but is highly variable across surveys.

- The relative prevalence of different indigenous parasitoid species attacking $H$. halys varies among habitat types.

16 Oregon Department of Agriculture, Insect Pest Prevention \& Management, Salem, OR, USA

17 Department of Entomology, University of California, Riverside, CA, USA

18 Department of Entomology, University of Maryland, College Park, MD, USA

19 Hudson Valley Research Laboratory, Cornell University, Highland, NY, USA

20 Department of Entomology, University of Arkansas, Fayetteville, AR, USA

21 Department of Entomology, Virginia Tech, Blacksburg, VA, USA

22 Horticultural Crops Research Unit, USDA Agricultural Research Service, Corvallis, OR, USA

23 Appalachian Fruit Research Station, USDA Agricultural Research Service, Kearneysville, WV, USA

24 Inst. Environmental \& Physical Sciences, Shepherd University, Shepherdstown, WV, USA
- Future work should include explicit measurements of population-level suppression of $H$. halys by biological control agents over the pest's entire life cycle.

\section{Introduction}

When developing a comprehensive management program for an invasive insect pest, one of the first steps is to determine levels of population suppression by predators and parasitoids native to the areas of introduction. These studies can inform the development of management practices that promote the conservation of effective indigenous natural enemies, as well as possible programs to introduce natural enemy species from the pest's area of origin (i.e., classical biological control). Communities of indigenous parasitoids and predators attacking invasive species (often serious pests) are thought to mostly be "generalists" (i.e., have a relatively wide host range), and to have limited population-level impact on the invader (Cornell and Hawkins 1993). However, these general trends are mostly based on datasets comprising small numbers of surveys restricted in their timeframe, geographic range, and habitat coverage. The identity and impact of indigenous natural enemies are likely to be variable and condition-dependent, differing among invaded regions, habitat types, and over time as natural enemies adapt to the new pest resource (Strayer et al. 2006; Berthon 2015). Invasive pests that have been the subject of repeated and widespread natural enemy surveys in several areas and habitats provide an opportunity to examine this variability.

The brown marmorated stink bug, Halyomorpha halys (Stål) (Hemiptera: Pentatomidae) has recently invaded large areas of North America and Europe (reviewed in Rice

25 Center for Grain and Animal Health Research, USDA Agricultural Research Service, Manhattan, KS, USA

26 Rutgers Agricultural Research \& Extension Center, Bridgeton, NJ, USA

27 Mountain Horticulture Research and Extension Center, North Carolina State University, Mills River, NC, USA

28 California Department of Food and Agriculture, Sacramento, CA, USA

29 Department of Entomology, Ohio State University, Columbus, OH, USA

30 Florida Department of Agriculture and Consumer Services, Division of Plant Industry/Entomology, Gainesville, FL, USA

31 Department of Agricultural, Forest and Food Sciences, University of Turin, Turin, Italy 
et al. 2014; Haye et al. 2015a), where it has become a serious agricultural pest as well as a nuisance problem for homeowners. Because of the significant economic impact of $H$. halys on a wide range of crops (e.g., field crops, vegetables, orchard fruit, ornamental plants) as well as use of many non-crop host plants in natural settings, there has been an intensive effort by a large number of researchers to characterize the identity and impact of indigenous natural enemy communities on $H$. halys. These natural enemy surveys have differed in their context and methodology (see below) and are ongoing as invasive $H$. halys populations continue to spread to new areas and the pest status of established populations changes. However, at this pointmore than 10 years after the first surveys of invasive $H$. halys populations were initiated-it was time to consolidate existing information from natural enemy surveys, with the following goals: (1) examine qualitative trends in indigenous natural enemy community composition and impact; (2) to identify research gaps and suggest directions for future research.

\section{Compilation of natural enemy survey data}

We initially compiled 115 field survey datasets from across North America and Europe (see Fig. 1 for geographic coverage of research teams), including published datasets (Jones et al. 2014; Haye et al. 2015b; Cornelius et al. 2016a, b; Herlihy et al. 2016; Lara et al. 2016; Morrison et al. 2016a, b; Ogburn et al. 2016; Roversi et al. 2016; Dieckhoff et al. 2017) and unpublished or in-preparation data collected by coauthors. We define a single "survey" as a unique combination of research team, $H$. halys life stage (egg, nymph, adult), crop or habitat type description (from the published papers and/or personal communications with primary researchers), and sampling method. Specific crop or habitat type descriptions for each survey were allocated to one of five "habitat categories": (1) field/vegetable crop (e.g., soybean, peppers, corn, tomato); (2) orchard (apple, peach); (3) ornamental (botanical gardens, nurseries); (4) forests (arboreal natural habitats); (5) semi-natural/urban (e.g., campuses, parks); or (6) mixed/unspecified. Sampling methods were defined based on whether $H$. halys life stages were placed in the habitat and then retrieved (sentinels), or if individuals were collected from the habitat and evaluated (naturally present). Sentinel egg mass surveys were further subdivided based on whether the egg masses were viable or frozen prior to deployment (to permit higher levels of parasitoid development, prevent $H$. halys emergence, and/ or to allow storage prior to deployment), as this methodology can affect what parasitoid species are detected (Haye et al. 2015b; Herlihy et al. 2016).

For each of the surveys, the following parameters were compiled, when available (most surveys did not measure every parameter): (1) total percentage parasitism evaluated by offspring emergence; (2) total percentage parasitism evaluated by combining emergence and dissections to detect unemerged and partially developed parasitoid offspring; (3) total percentage predation; (4) ranked prevalence of parasitoid species observed; and (5) ranked prevalence of predator species observed. Percentage parasitism and predation values were calculated on total number of individuals. When possible, multi-year datasets were pooled, with species ranks and mean percentage parasitism measurements weighted by relative sampling effort among years. Parasitoid and predator species were assigned rank scores based on total numbers and ranged from 5 (most prevalent) to 2 (fourth most prevalent). For surveys that observed more than 4 species, remaining species were all assigned a rank score of 1 . Individual surveys detecting adventive populations of the exotic Asian parasitoid Trissolcus japonicus (Ashmead) (Hymenoptera: Scelionidae) ( $n=17$ ) (Talamas et al. 2015; Herlihy et al. 2016; Milnes et al. 2016; Hedstrom et al. 2017; Morrison et al., in preparation) were excluded from subsequent analyses, as our goal was to evaluate surveys of indigenous natural enemy communities before incursion by this exotic parasitoid species. Thus, subsequent analyses of parasitism levels, predation levels, and species compositions draw from a total of 98 surveys (see Electronic Supplementary Material).

Combining and contrasting these studies with methodological differences including study site selection rationale, temporal period of study during each year, sentinel
Fig. 1 Geographic distribution of Halyomorpha halys natural enemy surveys included in this review (left panel North America, right panel Europe). Points represent the location of research teams, not individual study sites

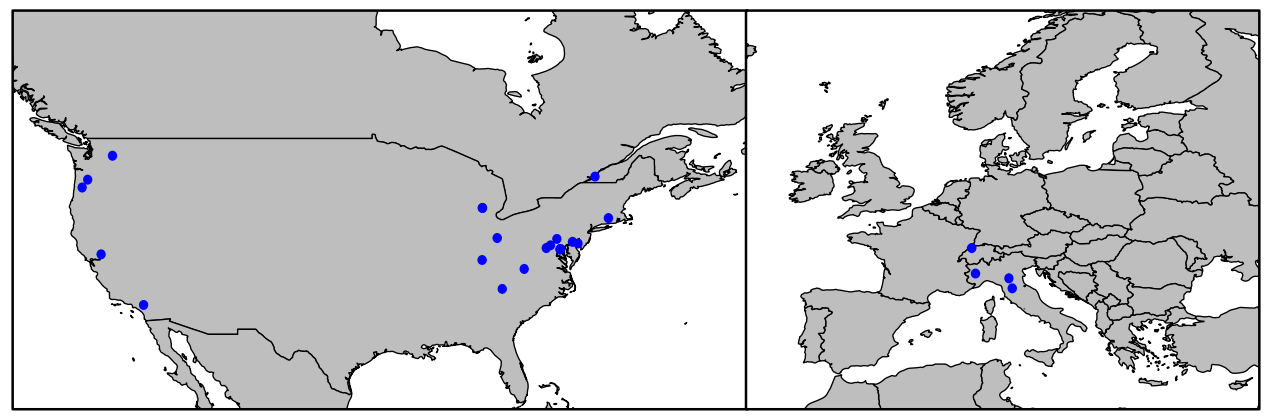


exposure and collection methodology (e.g., substrates for sentinel eggs, duration of sentinel field exposure, habitat definitions at field borders, dissection techniques, sampling effort) comes with obvious caveats. We also acknowledge that pooling of multi-year datasets precludes the analysis of temporal trends and among-year variability. However, these issues are examined in individual primary research studies with more uniform methodology. In light of these issues, we did not believe that any formal statistical analyses were justified; we instead aimed to identify general, qualitative trends whenever enough data were available to do so. In part, qualitative trends from this integrative analysis are expected to generate hypotheses to be tested by more controlled experimental studies in the future.

In the survey dataset, there were a considerable number ( $n=46)$ of North American studies examining egg parasitoid communities using viable egg masses (sentinel or naturally present) that identified at least one parasitoid species that emerged successfully from $H$. halys eggs. This permitted a qualitative evaluation of whether parasitoid species prevalence varied among habitat categories. For each habitat category, the consensus relative prevalence of each parasitoid species was determined as follows: (1) the rank scores of each parasitoid species were multiplied by the number of surveys in which the parasitoid obtained a given rank score; these values were summed to obtain a "prevalence value" for that species; and (2) the relative prevalence for each species was then calculated by dividing the species' prevalence value by the sum of all species' prevalence values in that habitat category. Thus, for a given habitat, all parasitoid species' relative prevalence values summed to 1 , reflecting a relative, weighted combination of how highly ranked each species tended to be in each habitat as well as how common a given parasitoid species was in the habitat category across different surveys (Fig. 2).

\section{General research focus and methodology of studies to date}

The number of surveys in our dataset with respect to $H$. halys life stage, habitat category, and sampling methodology is shown in Table 1. Notably, the vast majority (95\%) of studies in both North America and Europe have focused on the egg stage, with only two studies on natural enemies of nymphs and four focusing on adults.

Of the studies focused on eggs $(n=92), 58 \%$ evaluated viable sentinel eggs, $34 \%$ used frozen sentinel eggs, and $18 \%$ surveyed naturally present eggs (note that the total is more than $100 \%$ because some studies used a combination of viable and frozen sentinel eggs). In North America, most studies were conducted in field/vegetable crop (45\%) and semi-natural/urban $(20 \%)$ habitats, with fewer studies in forest, ornamental, orchard, and human dwelling settings. Reflecting the fact that there is typically a lag time before $H$. halys populations move into field crop habitats after initial detections, studies in Europe (which is more recently invaded than North America) have mostly taken place in semi-natural/urban, forested, and orchard habitats. Of all the natural enemy surveys focusing on $H$. halys eggs, $68 \%$ evaluated both parasitism and predation, $25 \%$ parasitism only, and $7 \%$ predation only. Of studies reporting mean egg parasitism levels $(n=80), 37.5 \%$ performed dissections to include unemerged (often dead at the time of dissection) and partially developed parasitoids; the remainder reported parasitism levels based on emerged parasitoid adults. Most measurements of parasitism levels included only recovered eggs in the calculation; only one sentinel egg study estimated the parasitism rate of unrecovered or eggs that were fed upon by predators using marginal rate analysis to partition attack rates between contemporaneous mortality factors (Herlihy et al. 2016). The majority of studies of natural enemies attacking nymphs and adults were based on naturally present individuals, although one study (Morrison et al. 2017) placed sentinel adults in spider webs inside human dwellings.

\section{Parasitoids of $\boldsymbol{H}$. halys}

\section{Parasitoids of $\boldsymbol{H}$. halys eggs}

Three principal groups of hymenopteran parasitoids attack $H$. halys eggs in invaded areas of North America and Europe: Scelionidae (Telenomus, Trissolcus, and Gryon spp.), Eupelmidae (Anastatus spp.), and Encyrtidae (Ooencyrtus spp.). The host range of the scelionids detected in these surveys, especially Telenomus (podisi group) and Trissolcus spp., tends to be restricted to stink bugs (Hemiptera: Pentatomidae) (Johnson 1984, 1987). Scelionid parasitoids of stink bug eggs have stereotyped patch exploitation and brood-guarding behavior, remaining on the patch for several hours after oviposition and engaging in aggressive inter- and intraspecific contests with other parasitoids (Field 1998). Eupelmids and encyrtids found attacking $H$. halys are likely to be generalists that attack multiple families of insect hosts and some species are facultative hyperparasitoids (Cusumano et al. 2013; Noyes 2017).

In agreement with the conclusions of past studies on $H$. halys and other stink bug species (Okuda and Yeargan 1988; Herlihy et al. 2016), our qualitative compilation of data from the USA supports the hypothesis that the relative prevalence of different parasitoid species associated with H. halys eggs is habitat-dependent (Fig. 2). Telenomus podisi Ashmead (Hymenoptera: Scelionidae) tends to 


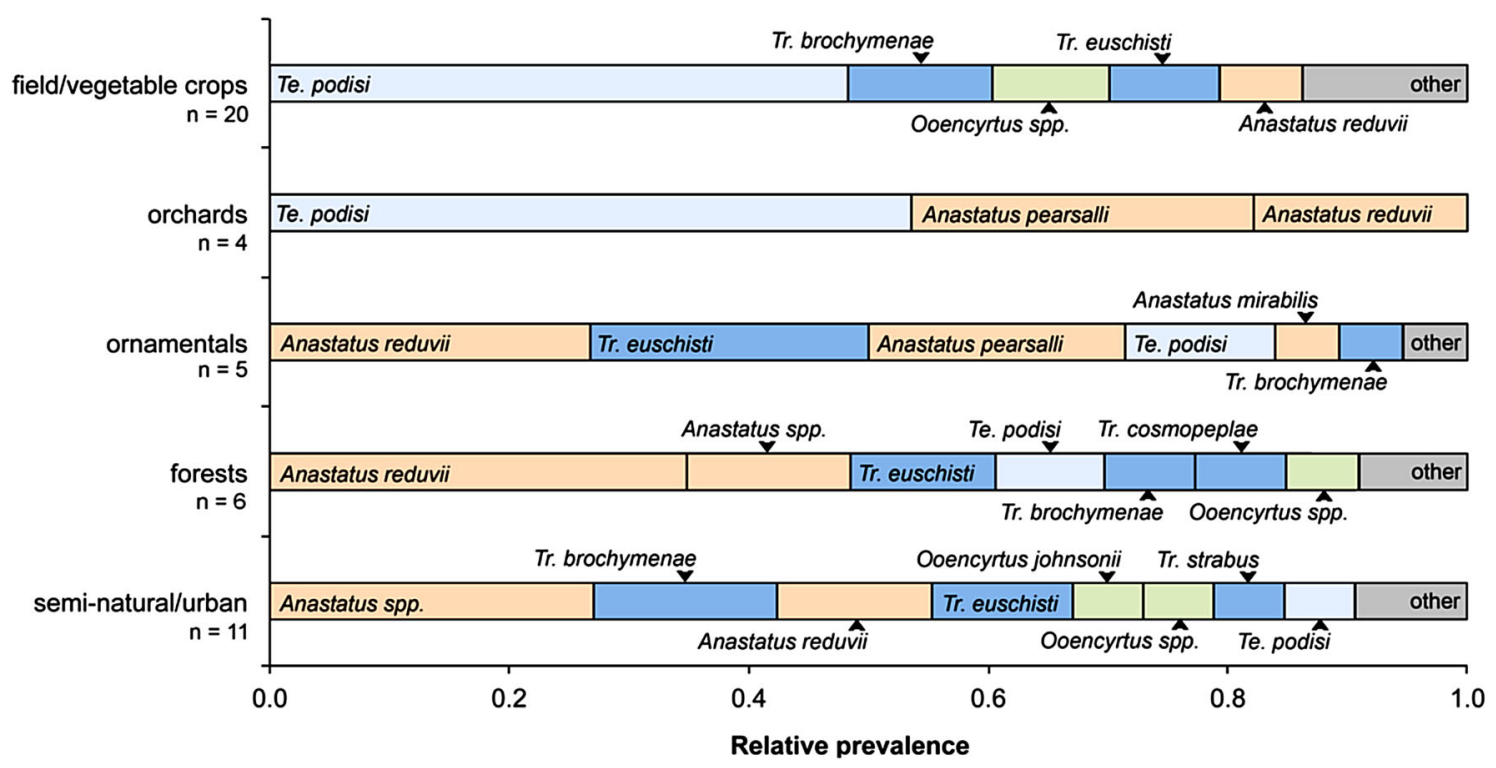

Fig. 2 Associations between relative prevalence (determined by a combination of relative rank and frequency among surveys) of different parasitoid species attacking viable Halyomorpha halys eggs by habitat category, based on 46 egg parasitoid surveys in the USA. For each habitat category, species are color-coded by parasitoid genus (orange = Anastatus spp.; light blue = Telenomus spp.; dark blue = Trissolcus spp.; green = Ooencyrtus spp.). Species not listed ("other"): field/vegetable crops-Tr. hullensis, Anastatus spp., Gryon obesum, Gryon stewartii; Tr. cosmopeplae; ornamentals-Tr. edessae, Ooencyrtus spp.; forests-Anastatus mirabilis, A. pearsalli, Te. persimilis, $T r$. edessae, $T r$. thyantae; semi-natural/urban-A. pearsalli, Tr. edessae. Not listed (from mixed/unspecified): Trissolcus flavipes. (Color figure online)

Table 1 Number of surveys for natural enemies of Halyomorpha halys in North America (NA) and Europe (EU) by life stage, sampling method (NP naturally present, SE sentinel), and habitat category (-indicates not applicable for given life stage)

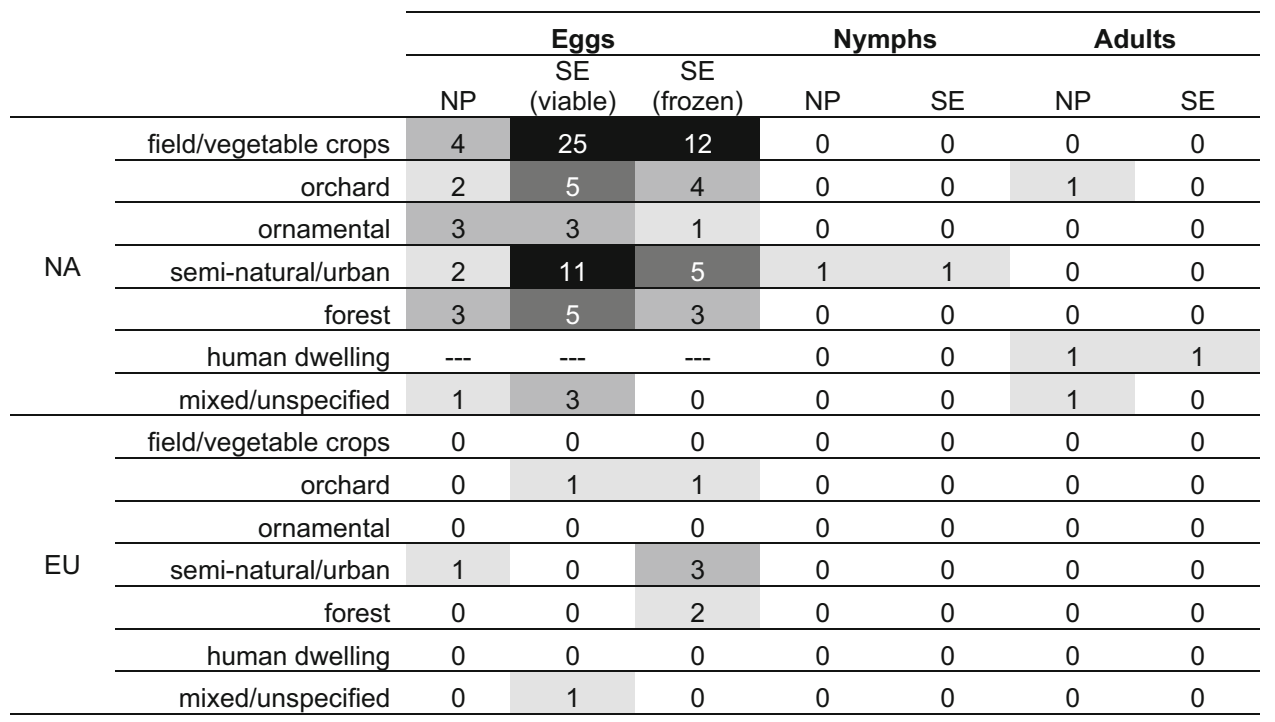

When surveys used a combination of frozen and viable sentinel eggs but did not separate the results $(n=10)$, a count is included in both SE (viable) and SE (frozen) categories. Darker cell shading is a visual aid to indicate more intense survey effort for a given life stage/methodology/ habitat

dominate field/vegetable crop and orchard habitats, while Anastatus (Hymenoptera: Eupelmidae) and Trissolcus (Hymenoptera: Scelionidae) make up most of the parasitoid community in ornamental, semi-natural/urban, and forest habitats. Habitat associations were not absolute, however, as several of the most commonly detected parasitoid species (e.g., A. reduvii [Howard], Tr. euschisti [Ashmead], Ooencyrtus spp., Te. podisi) were found at 
least once across several habitat types. A few of the most common parasitoid species (e.g., A. reduvii, Tr. euschisti) were found in both the western (Oregon, Washington, California) and central/eastern USA, although too little sampling has been conducted in the western USA to conclude whether species composition varies meaningfully between geographic regions. Parasitoid species emerging from frozen sentinel eggs in USA study sites were generally similar to viable eggs (data not shown), although one additional species, Telenomus utahensis (Ashmead), was identified in the western USA emerging from frozen sentinel eggs (JCL, unpublished data). The only two surveys in the dataset conducted in Canada did not observe any successful parasitoid emergence from frozen $H$. halys eggs, although $T e$. podisi were commonly found attending egg masses in both soybean and semi-natural/urban settings (PKA, unpublished data).

In Europe, there have not been enough surveys to compare parasitoid species prevalence across habitats. However, the genera of parasitoids attacking $H$. halys eggs are generally the same as in North America. Surveys in Switzerland and Italy have recorded $H$. halys egg parasitism by Anastatus bifasciatus (Geoffroy) (from both viable and frozen eggs), Trissolcus cultratus (Mayr) (frozen eggs), Ooencyrtus telenomicida (Vassiliev) (frozen eggs) (Roversi et al. 2016), and several unidentified Trissolcus and Telenomus spp. (Haye et al. 2015b; LM, EC, LT, unpublished data).

Egg parasitism levels measured on viable eggs pooled across all surveys were extremely variable, ranging from 0-59\% when based on parasitoid emergence; $28 \%$ of egg parasitoid surveys measured zero parasitoid emergence (Fig. 3), and emergence was lower than 5\% in $87 \%$ (46/53) of surveys. Surveys that included egg dissections in the measurement of parasitism levels tended to record higher parasitism rates (Fig. 3). In paired datasets that recorded both emerged and unemerged parasitoids (including partially developed offspring), the average increase in recorded parasitism from performing dissections was $6.16 \pm 1.52 \%$ $(n=30$; mean $\pm \mathrm{SE})$ and was as high as $36.5 \%$ in one case. Parasitism levels were not obviously different in freezekilled $H$. halys eggs compared to viable eggs overall (Fig. 3), although this trend contrasts with some standardized, paired comparisons in the literature (e.g., Herlihy et al. 2016; but see Ogburn et al. 2016). In agreement with the results of Jones et al. (2014) (whose data are part of this consolidated dataset), surveys of naturally present eggs recorded overall higher mean parasitism levels $(12.4 \pm 4.8 \%, n=12)$ than viable sentinel eggs $(1.1 \pm 0.2 \%, n=40)$, possibly because more semiochemical cues (host-associated kairomones on eggs and laying substrate, plant-emitted synomones; see Conti and Colazza 2012) are available to parasitoids to seek out naturally laid eggs.
A caveat to the above results is that surveys basing parasitism levels and parasitoid species composition on emergence from viable $H$. halys eggs do not detect many instances of unsuccessful parasitoid attack. Although this is probably the case for most natural enemy surveys in general, the disconnect between attack rates and parasitoid offspring emergence is particularly pronounced for indigenous parasitoids of $H$. halys in Europe and North America-especially Telenomus and Trissolcus spp. In the laboratory, both North American (Abram et al. 2014, 2016) and European (Haye et al. 2015b) scelionids readily accepted $H$. halys eggs for oviposition with little to no resulting offspring development. These findings have been supported by field studies that frequently find these parasitoids attending (i.e., guarding) sentinel egg masses-indicating that the parasitoid has oviposited several times in these egg masses (Field 1998; Abram et al. 2014; Haye et al. 2015b) —with low or zero offspring emergence (e.g., Cornelius et al. 2016a, b; PKA, EB, JM, KAH, unpublished data). As noted above (and in Fig. 3), dissecting unemerged sentinel eggs (e.g., Cornelius et al. 2016b; Dieckhoff et al. 2017) can help to detect some additional parasitoid attack; however, there are likely a considerable additional number of parasitoid ovipositions that leave no detectable visual evidence (Abram et al. 2014, 2016). Freeze-killed sentinel $H$. halys egg masses, through an unknown mechanism, can in some cases facilitate development of indigenous species of parasitoids and thus may also help to partially assess what species are unsuccessfully attacking egg masses (e.g., Haye et al. 2015b; Herlihy et al. 2016). Molecular diagnostic tools (see Gariepy et al. 2014) may be useful for detecting and quantifying rates of unsuccessful parasitoid attack on $H$. halys eggs.

Determining the prevalence of unsuccessful parasitoid oviposition in $H$. halys eggs in the field is important for several reasons. First, parasitoids accepting an unsuitable host at a high rate, considered an "egg sink" effect, could have indirect ecological effects that benefit shared hosts (i.e., indigenous stink bug species) (Heimpel et al. 2003; Abram et al. 2014). Second, laboratory studies have demonstrated that a considerable proportion ( $\sim 15-25 \%)$ of unsuccessful parasitoid ovipositions cause $H$. halys eggs to abort development with no visually detectable sign of parasitism (Abram et al. 2014; Haye et al. 2015b), implying that the biological control impact of indigenous egg parasitoids may have been systematically underestimated by natural enemy surveys (Abram et al. 2016). Indeed, several studies have noted that a significant proportion $(\sim 18-60 \%)$ of re-collected $H$. halys eggs do not emerge (e.g., Cornelius et al. 2016b; Ogburn et al. 2016; Dieckhoff et al. 2017; DB, ESD, LT, unpublished data). These egg mortality rates are usually 
Fig. 3 Box plots showing ranges of reported mean egg parasitism and predation levels of $H$. halys eggs (North America and Europe pooled). Horizontal lines show medians, boxes contain the 25th-75th percentiles, whiskers show the upper and lower deciles, and points show outliers. $V$ viable eggs (naturally present and sentinel pooled), $F$ frozen eggs. "Parasitoid development" includes emerged offspring as well as unsuccessful parasitism detected with dissections. Total natural enemy-induced mortality

(parasitism + predation) includes data from surveys that measured both parasitism and predation on viable eggs (for parasitism, parasitoid development values were used when available). Sample sizes refer to number of surveys

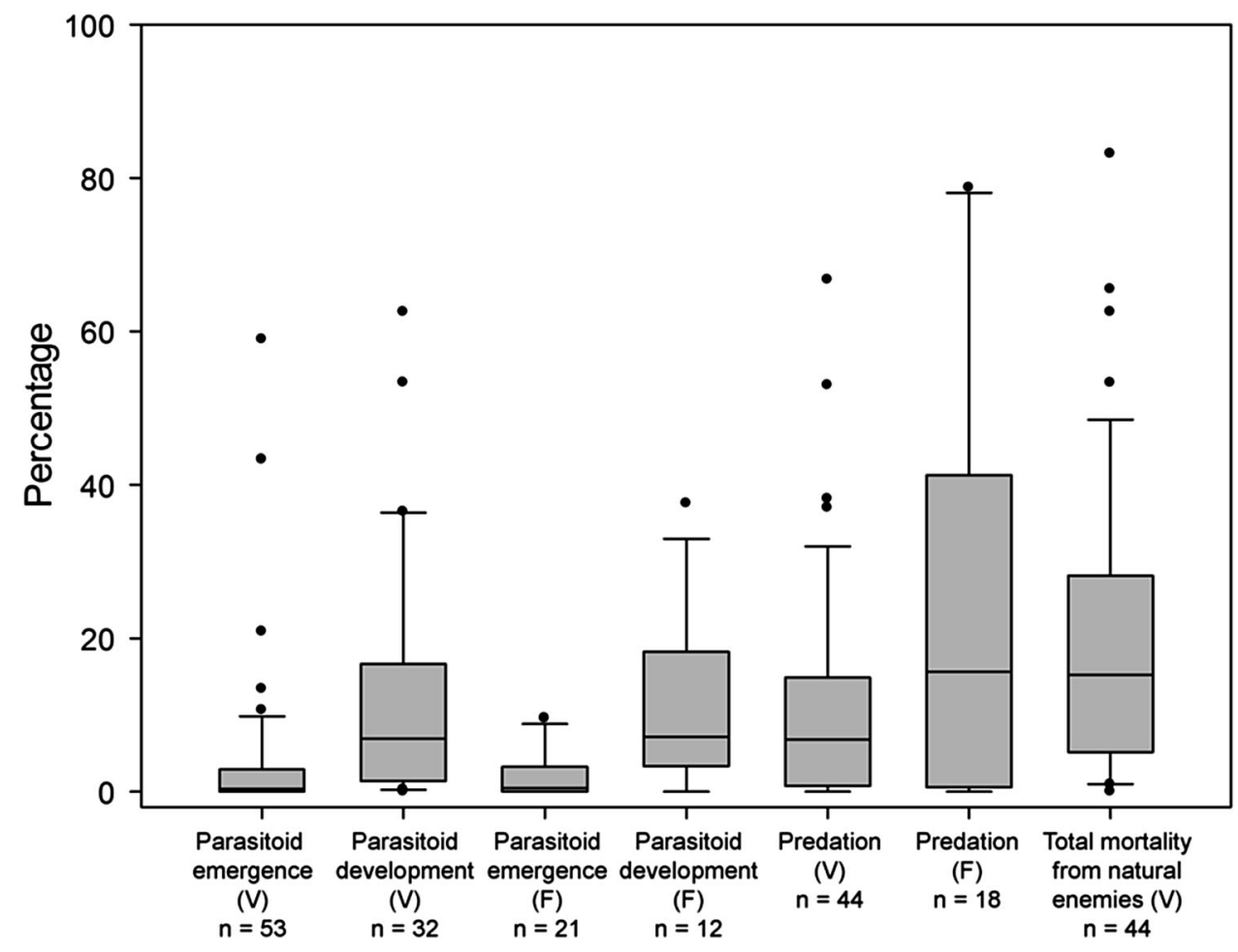

higher than baselines measured in the laboratory (but see Herlihy et al. 2016), which are between 15 and 20\% (e.g., Abram et al. 2016; Herlihy et al. 2016). It is unknown, however, what proportion of field mortality is due to abiotic factors (e.g., temperature, ultraviolet radiation) as opposed to parasitoid-induced host egg abortion. Estimating the true biological control impact of indigenous parasitoids, including $H$. halys eggs that were aborted by unsuccessful parasitoid ovipositions, will be a key challenge for future studies. To this end, we suggest that future egg parasitoid surveys should always include measurements of parasitoid emergence (successful progeny production), unsuccessful development (via dissection), and parasitoid-induced host egg abortion (by comparing developmental success of apparently unparasitized eggs with unattacked "control" eggs exposed under the same abiotic conditions; see also Abram et al. 2016).

\section{Parasitoids of $\boldsymbol{H}$. halys adults and nymphs}

Flies in the family Tachinidae are known to parasitize many species of stink bugs worldwide (Tschorsnig and Herting 1994; Aldrich et al. 2006). Surveys in the Northeastern USA collecting more than 25,000 H. halys adults from host plants and overwintering sites found tachinid eggs on low percentages of these adults (typically between 1 and $2 \%$; up to $12.5 \%$ in some collections). However, very low percentages $(<0.0001 \%)$ of $H$. halys adults brought into the laboratory had tachinid flies emerge from them, suggesting that fly offspring have low rates of developmental success (KAH, $\mathrm{CD}, \mathrm{DB}, \mathrm{NKJ}$ unpublished data). The only parasitoid species recorded emerging from $H$. halys adults to date is Trichopoda pennipes (Fabricius) (Diptera: Tachinidae) (DB, NKJ, unpublished data). A few studies have found that other tachinid species (e.g., Euclytia flava [Townsend]) are attracted to traps baited with $H$. halys aggregation pheromone (Lara et al. 2016; Morrison et al. 2016b), suggesting that these species may be seeking out and ovipositing on $H$. halys adults. To date, other than some observations of tachinid eggs on late-instar $H$. halys nymphs and exuviae (DB and NKJ, personal observations), there have been no parasitoids recorded from $H$. halys nymphs.

\section{Predators of $\boldsymbol{H}$. halys}

\section{Predators of $\boldsymbol{H}$. halys eggs}

The community of indigenous generalist predators consuming $H$. halys eggs is very diverse, made up of many species with a variety of modes of feeding. While the majority of surveys in our dataset that measured levels of predation did not identify the predators responsible for $H$. halys egg mortality, a few recent studies have made significant progress in this direction using a variety of methodological approaches.

Morrison et al. (2016a) identified four distinct predation "syndromes" on $H$. halys eggs using laboratory 
observations of over 25 predator taxa: (1) complete chewing-eggs completely removed from substrate; (2) incomplete chewing-egg shell debris from predated eggs remains on substrate; (3) stylet sucking-presence of a feeding sheath in eggs drained of their contents; and (4) punctured sucking - a hole or slit in hollowed-out eggs. In the laboratory, the most efficient predators were katydids (Orthoptera: Tettigoniidae), ground beetles (Coleoptera: Carabidae), crickets (Orthoptera: Gryllidae), earwigs (Dermaptera: Forficulidae), and jumping spiders (Araneae: Salticidae). The categorization system above was then applied to sentinel egg masses deployed in several agroecosystems in which these predators were present and distinguished from abiotic mortality factors using "control" (caged) sentinel eggs. The most common predation syndrome in the field was complete chewing, associated with potentially incidental consumption by predators such as katydids and crickets, highlighting the fact that "missing" or "lost" egg masses in other studies were likely the result of predation. It is worth noting that unpublished studies in our survey dataset have observed higher levels of stylet and punctured sucking predation than chewing predation in some cases. However, this may be because eggs completely removed from the substrate were not scored as predation. Further conclusions by Morrison et al. (2016a), in agreement with past laboratory studies (Abram et al. 2015), were that the ability of predators to consume $H$. halys eggs is often life-stage-specific, and that some common and abundant chewing predators, including all life stages of ladybird beetles (Coleoptera: Coccinellidae) are generally ineffective predators of $H$. halys eggs. Other common predators observed in the surveys compiled here include green lacewings (Neuroptera: Chrysopidae), predatory mirid bugs (Hemiptera: Miridae), cockroaches (Blattodea: Blattidae) and ants (Hymenoptera: Formicidae) (see Rice et al. 2014 for another review).

Other approaches being used to determine $H$. halys predators include camera trap imaging of egg predation and remaining eggs (CHP, unpublished data), digital video recording of sentinel egg masses (KP, MG, JP and ALN, in preparation), and molecular gut content analysis (JP and ALN, in preparation). Digital video recording of field-exposed sentinel egg masses has allowed family-level identification of predators and confirmed that "complete chewing" omnivores such as earwigs, katydids, crickets, and grasshoppers (Orthoptera: Acrididae) and "stylet sucking" groups such as predatory pentatomids are some of the most common predators of $H$. halys eggs. At this time, there have not been enough direct predator identifications to identify trends in relative prevalence among habitats. In addition, no egg predator surveys from Europe have been published to date, although sentinel egg mass studies in
Switzerland have noted large proportions of "missing" eggs, probably due to predation (Haye et al. 2015b).

Predation levels measured on viable $H$. halys eggs were usually less than $15 \%$, although in a few cases they exceeded $30 \%$ (Fig. 3). In general, these values spanned a similar range to parasitism values where dissections were included. Higher $(>20 \%)$ predation levels were more common on frozen eggs, in agreement with some alreadypublished comparisons (e.g., Ogburn et al. 2016), although the reason for this trend is unknown.

\section{Predators of $\boldsymbol{H}$. halys adults and nymphs}

Predators attacking $H$. halys adults and nymphs in Europe and North America have not been extensively studied. In one study of the nest-provisioning wasp Bicyrtes quadrifasciata (Say) (Hymenoptera: Crabronidae) in the northeastern USA, $H$. halys nymphs made up $96 \%$ of the prey provided to developing offspring (Biddinger et al. 2017). Another crabronid wasp, Astata unicolor Say, was also observed preying on $H$. halys nymphs in this region (DB and JN, in preparation), and traps baited with a two-component mixture including mixed murgantiol (containing $H$. halys aggregation pheromone) and (E,E,Z)-2,4,6-methyldecatrienoate (MDT) were observed to attract Astata sp. in California (Lara et al. 2016). Jones (2013) commonly observed predation of $H$. halys adults and nymphs by the wheel bug Arilus cristatus (L.) (Hemiptera: Reduviidae) in Maryland, USA. Predation of adult $H$. halys by praying mantids (Mantodea: Mantidae) has also been observed on a number of occasions in the USA (TPK and TCL, unpublished data). Interestingly, only one unpublished study has gathered some information on the consumption of newly emerged (1st instar) $H$. halys nymphs, which are clustered on egg masses for several days and potentially vulnerable as they are relatively immobile and soft-bodied. That study observed the highest predation of freshly emerged first instar nymphs in the laboratory by field-collected Carabidae ( $89 \%$ of nymphs emerged were eaten), predatory Pentatomidae (88\%), Salticidae (35\%), and Reduviidae (26\%; WRM, CM, TCL, unpublished data).

Morrison et al. (2017) conducted the first study of adult $H$. halys predation by web-building spiders in and outside human dwellings. They found that several families of spiders (particularly Theridiidae, Pholcidae, and Agelenidae) were particularly adept at ensnaring and consuming $H$. halys adults. Furthermore, a considerable percentage (13-20\%) of surveyed spider webs contained dead $H$. halys adults, suggesting that spiders may represent a significant biotic mortality factor in natural settings, as well as when the pest enters and exits human dwellings for overwintering. 


\section{Research gaps and future directions}

Despite the large amount of work conducted to date on indigenous natural enemies of $H$. halys in invaded areas, many questions have still not been fully addressed. We divide proposed areas of future focus into five categories: (1) determining population-level impact; (2) intraguild interactions; (3) natural enemy adaptation; (4) chemical ecology; and (5) integrating natural enemies into pest management programs.

\section{Determining population-level impact}

To date, surveys for natural enemies of $H$. halys have all estimated biological control impact by measuring the percentage of a given life stage (mostly eggs) killed by natural enemies. While percentage parasitism/predation can be a useful proxy of biological control efficacy, these measurements do not directly indicate true population-level impact, i.e., the degree to which natural enemies are reducing pest population growth (Van Driesche 1983). This is because the relative contribution of mortality during any one stage to total generational pest mortality depends on the magnitude and timing of other factors over the entire life cycle of the pest. For example, the importance of $H$. halys egg mortality due to parasitism and predation (typically 5-25\%) in reducing generational population growth would depend on to what degree predation and parasitism act additively during the egg stage as well as the magnitude of mortality factors acting later in the life cycle (i.e., on nymphs and adults, which are seldom studied). To better estimate true biological control impact on $H$. halys, life table studies (see Bellows and Van Driesche 1999) using marginal rates of mortality (Elkinton et al. 1992), and cage exclusion experiments (e.g., Gardiner et al. 2009) to measure $H$. halys population growth in the presence and absence of natural enemies over as much of the life cycle as possible are needed. We also refer readers to MacFadyen et al. (2015), who discuss the rarity of measurements of true biological control impact and provide a complementary discussion of this issue and potential solutions. What is clear, however, is that up to this point indigenous natural enemy impact on $H$. halys in North America and Europe has often been insufficient in reducing this pest to subeconomic levels. In contrast, $H$. halys egg parasitism levels measured in its area of origin (China) are consistently high over the course of the season (70-90\%) and are associated with lower $H$. halys pest pressure (Yang et al. 2009; Zhang et al. 2017; KAH, in preparation). As adventive populations of the parasitoid primarily responsible for this parasitism in Asia (Tr. japonicus) continue to spread and establish in eastern (Talamas et al. 2015; Morrison et al. in prep) and western (Milnes et al. 2016; Hedstrom et al. 2017) North America and interact with indigenous biological control agents (see next section), it will be important to measure its biological control impact in the context of the entire life cycle of $H$. halys.

\section{Intraguild interactions}

Trophic and competitive interactions among different natural enemies of $H$. halys are likely to influence biological control outcomes (Rosenheim et al. 1995). Relevant intraguild interactions could include those (1) between parasitoids and predators (including native predatory pentatomids), (2) among indigenous parasitoids, and (3) between indigenous and exotic parasitoids. The first two categories of interactions have not been addressed in the literature to our knowledge. However, two studies have investigated outcomes of competitive interactions between indigenous European parasitoids and the exotic Asian parasitoid $T r$. japonicus, with somewhat unexpected but very interesting results. Konopka et al. (2017a) found that European Tr. cultratus (which cannot normally develop successfully in $H$. halys eggs) can act as a hyperparasitoid on eggs previously parasitized by $T r$. japonicus, but only during a certain window of opportunity late in $T r$. japonicus larval development. Thus, if this finding extends to other indigenous parasitoid species in North America and Europe, Tr. japonicus could act as an "invasional lifeline," allowing indigenous parasitoids to successfully complete development in some H. halys eggs (Konopka et al. 2017a). The situation was different in the case of interactions between $T r$. japonicus and the indigenous European parasitoid A. bifasciatus (Konopka et al. 2017b). Because of its higher aggression levels, $T r$. japonicus was the superior extrinsic competitor, excluding A. bifasciatus from $H$. halys egg masses when adults of both species were present at the same time. However, A. bifasciatus was always the superior intrinsic competitor, with its offspring emerging from multi-parasitized eggs regardless of parasitism intervals. This combination of factors, along with egg load differences between the two species, led the authors to conclude that these two parasitoid species could likely coexist without compromising biological control of $H$. halys (Konopka et al. 2017b). While future studies continue to explore these interactions in other invaded areas and with other species combinations, there are additional ecological issues that will need to be explored. For example, our review suggests that parasitoid species composition will vary by habitat, which would determine whether and with what relative frequency these intraguild interactions would be likely to occur. 


\section{Adaptation}

Following invasions and the subsequent rapid increase in abundance of invasive species, indigenous natural enemies often fail to immediately include the invasive species in their host/prey repertoire and can sometimes show maladaptive responses, leading to "evolutionary traps" (Schlaepfer et al. 2005). However, these situations may often be temporary; in some cases indigenous species have been shown to develop behavioral, morphological, or physiological adaptations that allow them to use the invader as a resource and/or mitigate its negative effects (Berthon 2015). Indigenous scelionid parasitoids of $H$. halys, which attack its eggs at high rates, but often cannot successfully develop (see above) must be subject to an enormous selective pressure to either avoid ovipositing in this novel host (i.e., evolve behavioral avoidance), or to evolve the physiological capacity to develop successfully. A recent study in the northeastern USA, where $H$. halys has now been present for at least 15 years, measured high rates of partial development (and some successful development) of the parasitoid $T e$. podisi, and suggested that this species may be starting to adapt to develop in the invasive host (Cornelius et al. 2016b). To confirm this hypothesis, longterm longitudinal studies and/or chronosequences (i.e., studies at sites differing in their time since $H$. halys invasion) would need to be conducted (Strayer et al. 2006). To accelerate this process, it may also be possible to initiate breeding programs to artificially select strains of indigenous parasitoids with increased developmental success on H. halys.

\section{Chemical ecology}

There is some understanding of the hierarchy of hostderived cues mediating host finding by natural enemies of stink bugs, particularly scelionid egg parasitoids (reviewed in Conti and Colazza 2012). These include herbivory and oviposition-induced plant synomones, vibrational signals, mating and aggregation pheromones, cuticular hydrocarbons deposited on substrates ("chemical footprints"), and volatile and contact kairomones present on eggs. Only a few published studies have examined indigenous natural enemy response to $H$. halys-derived semiochemicals (see also Weber et al. 2017). Fraga et al. (2017) found that minute pirate bugs, Orius insidiosus (Say) (Hemiptera: Anthocoridae), are attracted to bean pods damaged by $H$. halys and traps baited with the major chemical component emitted from nymphs and adults (tridecane), although attraction to these compounds did not lead to increased egg predation. Tognon et al. (2016) identified $H$. halys egg volatiles that could influence the behavior of indigenous parasitoids and, surprisingly, concluded that they may actually be repulsive, at least under their test conditions. Morrison et al. (in prep.) provided evidence that native natural enemies do not use the $H$. halys aggregation pheromone-nor a number of other cues/host stimuli-as host-finding cues. Another recent study (Rondoni et al. 2017) suggests that some indigenous European parasitoids (A. bifasciatus, O. telenomicida), but not others ( $T r$. basalis), are attracted to volatiles emitted by host plants attacked by $H$. halys. Much more work is needed to understand if or how indigenous natural enemies respond to chemical cues derived from $H$. halys, how this compares to the host location abilities of co-evolved parasitoids (e.g., $T r$. japonicus), and how their responses to these cues affects biological control efficacy.

\section{Pest management}

Current management tactics for $H$. halys mostly rely on insecticide applications (Rice et al. 2014; Kuhar and Kamminga 2017). As indigenous parasitoids and predators adapt to $H$. halys and exotic parasitoids continue to spread and establish, biological control is expected to become an increasingly important component of integrated pest management programs. The fact that such marked differences in parasitoid species composition exist among habitats (Fig. 2), for example, imply that landscape structure and vegetation have the potential to influence biological control communities and their impact. At present, there are no published studies of how landscape factors or proposed alternative on-farm management practices (e.g., attractand-kill-Morrison et al. 2016c; trap crops-Mathews et al. 2017; border and alternate-row spraying-Leskey et al. 2012, Blaauw et al. 2015; insecticide-incorporated nets-Kuhar et al. 2017) influence indigenous natural enemies and their impact $H$. halys population growth. To assess the effect of these pest management practices on biological control services, future studies will need to integrate accurate measurements of population-level impact with chemical, behavioral, and invasive species ecology.

\section{Authors' contribution}

PKA and KAH conceived of and coordinated the review. PKA compiled the data and wrote the first draft of the manuscript. All authors contributed data, revised the manuscript, and approved the manuscript.

Acknowledgements The authors wish to thank the following for research assistance collecting data used in this review: Clint Fleshman, Dana Martin, Chad Kramer, Lindsay Stump, Chelsea Berish, Sarah Detraz, Waydon Yates, the UKY farm crew, Emma Thrift, Treva Rowley, Nathan Erwin, Rose Borror, Zachary Johnson, Heather 
Leach, Megan Lowlor, Brooke Merrill, Devon Newsom, Gary Parason, Ryan Paul, Trisha Samota, McKenzie Allen, Brittany Poling, Morgan Douglas, Samuel Brandt, Torri Hancock, John Cullum, Adam Cave, Tina Dancau, Dennis Quach, Chris Hughes, Lot Miller, Kathy Wholaver, Katy Ellis, Silvia T. Moraglio, Marco G. Pansa, Kathy Tatman, Kylie Mendonca, Kody Transue, Max Sinton, Andrew Lyons, Elizabeth Fread, Abigail Rosenburg, Jeremy Turner, and Steve Schoof. We thank the following grower cooperators: Jeff Dickinson, Mike Laughlin, Sue Borton, Guy Ashmore, Redbud Farm, Barry Rice, and Scott Slaybaugh. Funding for the work synthesized in this review includes grants from the USDA-NIFA-OREI No. 2012-51300-20097; USDA-NIFA-SCRI Nos. 2011-51181-30937; USDA NE-1032 Multistate Hatch Project; Federally funded Specialty Crop Block Grant 13054, administered by the California Department of Food \& Agriculture; State Horticultural Association of Pennsylvania; Pennsylvania State University Hatch Project No. Pen04619. The USDA does not endorse any commercial product mentioned in this research. USDA is an equal opportunity provider and employer.

\section{Compliance with ethical standards}

Conflict of interest The authors have declared that no conflict of interest exists.

Ethical approval All applicable international, national, and/or institutional guidelines for the care and use of animals were followed. This article does not contain any studies with human participants performed by any of the authors.

\section{References}

Abram PK, Gariepy TD, Boivin G, Brodeur J (2014) An invasive stink bug as an evolutionary trap for an indigenous egg parasitoid. Biol Invasion 16:1387-1395

Abram PK, Doyon J, Brodeur J, Gariépy TD, Boivin G (2015) Susceptibility of Halyomorpha halys (Hemiptera: Pentatomidae) eggs to different life stages of three generalist predators. Can Entomol 147:222-226

Abram PK, Brodeur J, Burte V, Boivin G (2016) Parasitoid-induced host egg abortion: an underappreciated component of biological control services provided by egg parasitoids. Biol Control 98:52-60

Aldrich JR, Khrimian A, Zhang A, Shearer PW (2006) Bug pheromones (Hemiptera, Heteroptera) and tachinid fly hostfinding. Denisia 19:1015-1031

Bellows TS, Van Driesche RG (1999) Life table construction and analysis for evaluating biological control agents. In: Bellows TS, Fisher TW (eds) Handbook of biological control, pp 199-203

Berthon K (2015) How do native species respond to invaders? Mechanistic and trait-based perspectives. Biol Invasion 17:2199-2211

Biddinger DJ, Surcică A, Joshi NK (2017) A native predator utilizing the invasive brown marmorated stink bug, Halyomorpha halys (Hemiptera: Pentatomidae) as a food source. Biocontrol Sci Technol (in press)

Blaauw BR, Polk D, Nielsen AL (2015) IPM-CPR for peaches: incorporating behaviorally-based methods to manage Halyomorpha halys and key pests in peach. Pest Manag Sci 71:1513-1522

Conti E, Colazza S (2012) Chemical ecology of egg parasitoids associated with true bugs. Psyche. doi:10.1155/2012/651015

Cornelius ML, Dieckhoff C, Vinyard BT, Hoelmer KA (2016a) Parasitism and predation on sentinel egg masses of the brown marmorated stink bug (Hemiptera: Pentatomidae) in three vegetable crops: importance of dissections for evaluating the impact of native parasitoids on an exotic pest. Environ Entomol 45:1536-1542

Cornelius ML, Dieckhoff C, Hoelmer KA, Olsen RT, Weber DC, Herlihy MV, Talamas EJ, Vinyard BT, Greenstone MH (2016b) Biological control of sentinel egg masses of the exotic invasive stink bug Halyomorpha halys (Stål) in Mid-Atlantic USA ornamental landscapes. Biol Control 103:11-20

Cornell HV, Hawkins BA (1993) Accumulation of native parasitoid species on introduced herbivores: a comparison of hosts as natives and hosts as invaders. Am Nat 141:847-865

Cusumano A, Peri E, Amodeo V, McNeil JN, Colazza S (2013) Intraguild interactions between egg parasitoids: window of opportunity and fitness costs for a facultative hyperparasitoid. PLoS ONE 8:e64768

Dieckhoff C, Tatman K, Hoelmer KA (2017) Natural biological control of Halyomorpha halys by native egg parasitoids-a multi-year survey in northern Delaware. J Pest Sci. doi:10.1007/ s10340-017-0868-6

Elkinton JS, Buonaccorsi JP, Bellows TS, Van Driesche RG (1992) Marginal attack rate, k-values and density dependence in the analysis of contemporaneous mortality factors. Res Popul Ecol 34:29-44

Field SA (1998) Patch exploitation, patch-leaving and pre-emptive patch defence in the parasitoid wasp Trissolcus basalis (Insecta: Scelionidae). Ethology 104:323-338

Fraga DF, Parker J, Busoli AC, Hamilton GC, Nielsen AL, Rodriguez-Saona C (2017) Behavioral responses of predaceous minute pirate bugs to tridecane, a volatile emitted by the brown marmorated stink bug. J Pest Sci. doi:10.1007/s10340-016-08259

Gardiner MM, Landis DA, Gratton C, DiFonzo CD, O’Neal M, Chacon JM, Wayo MT, Schmidt NP, Mueller EE, Heimpel GE (2009) Landscape diversity enhances biological control of an introduced crop pest in the north-central USA. Ecol Appl 19:143-154

Gariepy TD, Haye T, Zhang J (2014) A molecular diagnostic tool for the preliminary assessment of host-parasitoid associations in biological control programmes for a new invasive pest. Mol Ecol 23:3912-3924

Haye T, Gariepy T, Hoelmer K, Rossi JP, Streito JC, Tassus X, Desneux N (2015a) Range expansion of the invasive brown marmorated stinkbug, Halyomorpha halys: an increasing threat to field, fruit and vegetable crops worldwide. J Pest Sci 88:665-673

Haye T, Fischer S, Zhang J, Gariepy TD (2015b) Can native egg parasitoids adopt the invasive brown marmorated stink bug, Halyomorpha halys (Heteroptera: Pentatomidae), in Europe? J Pest Sci 88:693-705

Hedstrom CH, D Lowenstein, H Andrews, B Bai, and NG Wiman (2017) Pentatomid host suitability and the discovery of introducedpopulations of Trissolcus japonicus in Oregon. J Pest Sci. doi:10.1007/s10340-017-0892-6

Heimpel GE, Neuhauser C, Hoogendoorn M (2003) Effects of parasitoid fecundity and host resistance on indirect interactions among hosts sharing a parasitoid. Ecol Lett 6:556-566

Herlihy MV, Talamas EJ, Weber DC (2016) Attack and success of native and exotic parasitoids on eggs of Halyomorpha halys in three Maryland habitats. PLoS ONE 11:e0150275

Johnson N (1984) Systematics of Nearctic Telenomus: classification and revisions of the podisi and phymatae species groups (Hymenoptera: Scelionidae). Bull Ohio Biol Surv 6:1-112

Johnson N (1987) Systematics of New World Trissolcus, a genus of pentatomid egg-parasites (Hymenoptera: Scelionidae): Neotropical species of the flavipes group. J Nat Hist 21:285-304

Jones A (2013) Indigenous natural enemies of the invasive brown marmorated stink bug, Halyomorpha halys (Hemiptera: 
Pentatomidae). Department of Entomology, University of Maryland, College Park, Master of Science, p 62

Jones AL, Jennings DE, Hooks CRR, Shrewsbury PM (2014) Sentinel eggs underestimate rates of parasitism of the exotic brown marmorated stink bug, Halyomorpha halys. Biol Control 78:61-66

Konopka JK, Haye T, Gariepy T, Mason PG, Gillespie DR, McNeil JN (2017a) An exotic parasitoid provides an invasional lifeline for native parasitoids. Ecol Evol 7:277-284

Konopka JK, Haye T, Gariepy TD, McNeil JN (2017b) Possible coexistence of native and exotic parasitoids and their impact on control of Halyomorpha halys. J Pest Sci. doi:10.1007/s10340017-0851-2

Kuhar TP, Kamminga K (2017) Review of the chemical control research on Halyomorpha halys in the United States. J Pest Sci. doi:10.1007/s10340-017-0859-7

Kuhar TP, Short BD, Krawczyk G, Leskey TC (2017) Deltamethrinincorporated nets as an integrated pest management tool for the invasive Halyomorpha halys (Hemiptera: Pentatomidae). J Econ Entomol. doi:10.1093/jee/tow321

Lara R, Pickett C, Ingels C, Haviland DR, Grafton-Cardwell E, Doll D, Bethke J, Faber B, Dara SK, Hoddle M (2016) Biological control program is being developed for brown marmorated stink bug. Calif Agric 70:15-23

Leskey TC, Short BD, Butler BR, Wright SE (2012) Impact of the invasive brown marmorated stink bug, Halyomorpha halys (Stål), in mid-Atlantic tree fruit orchards in the United States: case studies of commercial management. Psyche. doi:10.1155/ 2012/535062

MacFadyen S, Davies AP, Zalucki MP (2015) Assessing the impact of arthropod natural enemies on crop pests at the field scale. Insect Sci 22:20-34

Mathews CR, Blaauw B, Dively G, Kotcon J, Moore J, Ogburn E, Pfeiffer DG, Trope T, Walgenbach JF, Welty C, Zinati G, Nielsen AL (2017) Evaluating a polyculture trap crop for organic management of Halyomorpha halys and native stink bugs in peppers. J Pest Sci. doi:10.1007/s10340-017-0838-z

Milnes JM, Wiman NG, Talamas EJ, Brunner JF, Hoelmer KA, Buffington ML, Beers EH (2016) Discovery of an exotic egg parasitoid of the brown marmorated stink bug, Halyomorpha halys (Stål) in the Pacific Northwest. Proc Entomol Soc Wash 118:466-470

Morrison WR III, Mathews CR, Leskey TC (2016a) Frequency, efficiency, and physical characteristics of predation by generalist predators of brown marmorated stink bug (Hemiptera: Pentatomidae) eggs. Biol Control 97:120-130

Morrison WR III, Park C-G, Seo BY, Park Y-L, Kim HG, Rice KB, Lee D-H, Leskey TC (2016b) Attraction of the invasive Halyomorpha halys in its native Asian range to traps baited with semiochemical stimuli. J Pest Sci. doi:10.1007/s10340-0160816-X

Morrison WR III, Lee DH, Short BD, Khrimian A, Leskey TC (2016c) Establishing the behavioral basis for an attract-and-kill strategy to manage the invasive Halyomorpha halys in apple orchards. J Pest Sci 89:81-96

Morrison WR III, Bryant AN, Poling B, Quinn NF, Leskey TC (2017) Predation of Halyomorpha halys (Hemiptera: Pentatomidae) from web-building spiders associated with anthropogenic dwellings. J Insect Behav 30:70-85

Noyes JS (2017) Universal Chalcidoidea Database. World Wide Web electronic publication. http://www.nhm.ac.uk/chalcidoids. Accessed 30 Mar 2017
Ogburn EC, Bessin R, Dieckhoff C, Dobson R, Grieshop M, Hoelmer KA, Matthews C, Moore J, Nielsen AL, Poley K, Pote JM, Rogers M, Welty C, Walgenbach JF (2016) Natural enemy impact on eggs of the invasive brown marmorated stink bug, Halyomorpha halys (Stål)(Hemiptera: Pentatomidae), in organic agroecosystems: a regional assessment. Biol Control 101:39-51

Okuda MS, Yeargan KV (1988) Habitat partitioning by Telenomus podisi and Trissolcus euschisti (Hymenoptera: Scelionidae) between herbaceous and woody host plants. Environ Entomol 17:795-798

Rice KB, Bergh CJ, Bergmann EJ, Biddinger DJ, Dieckhoff C, Dively G, Fraser H, Gariepy TD, Hamilton G, Haye T, Herbert A, Hoelmer KA, Hooks CR, Jones A, Krawczyk G, Kuhar T, Martinson H, Mitchell W, Nielsen AL, Pfeiffer DG, Raupp M, Rodrigues-Saona C, Shearer P, Shrewsbury P, Venugopal PD, Whalen J, Wiman NG, Leskey TC, Tooker JF (2014) Biology, ecology, and management of brown marmorated stink bug (Hemiptera: Pentatomidae). J Integr Pest Manag 5:A1-A13

Rondoni G, Bertoldi V, Malek R, Foti MC, Peri E, Maistrello L, Haye T, Conti E (2017) Native egg parasitoids recorded from the invasive Halyomorpha halys successfully exploit volatiles emitted by the plant-herbivore complex. J Pest Sci. doi:10.1007/ s10340-017-0861-0

Rosenheim JA, Kaya HK, Ehler LE, Marois JJ, Jaffee BA (1995) Intraguild predation among biological-control agents: theory and evidence. Biol Control 5:303-335

Roversi PF, Binazzi F, Marianelli L, Costi E, Maistrello L, Sabbatini Peverieri G (2016) Searching for native egg-parasitoids of the invasive alien species Halyomorpha halys Stål (Heteroptera, Pentatomidae) in Southern Europe. Redia 99:63-70. doi:10. 19263/REDIA-99.16.01

Schlaepfer MA, Sherman PW, Blossey B, Runge MC (2005) Introduced species as evolutionary traps. Ecol Lett 8:241-246

Strayer DL, Eviner VT, Jeschke JM, Pace ML (2006) Understanding the long-term effects of species invasions. TREE 21:645-651

Talamas EJ, Herlihy MV, Dieckhoff C, Hoelmer KA, Buffington M, Bon M-C, Weber DC (2015) Trissolcus japonicus (Ashmead)(Hymenoptera, Scelionidae) emerges in North America. J Hymenopt Res 43:119-128

Tognon R, SantAna J, Zhang QH, Millar JG, Aldrich JR, Zalom FG (2016) Volatiles mediating parasitism of Euschistus conspersus and Halyomorpha halys eggs by Telenomus podisi and Trissolcus erugatus. J Chem Ecol 42:1016-1027

Tschorsnig HP, Herting B (1994) The tachinids (Diptera: Tachinidae) of central Europe: identification keys for the species and data on distribution and ecology. Stuttgarter Beiträge zur Naturkunde, Serie A (Biol.), p 150

Van Driesche RG (1983) Meaning of "percent parasitism" in studies of insect parasitoids. Environ Entomol 12:1611-1622

Weber DC, Morrison WR III, Khrimian A, Rice K, Leskey TC, Rodriguez-Saona C, Nielsen AL, Blaauw BR (2017) Chemical ecology of Halyomorpha halys: discoveries and applications. J Pest Sci. doi:10.1007/s10340-017-0876-6

Yang ZQ, Yao YX, Qiu LF, Li ZX (2009) A new species of Trissolcus (Hymenoptera: Scelionidae) parasitizing eggs of Halyomorpha halys (Heteroptera: Pentatomidae) in China with comments on its biology. Ann Entomol Soc Am 102:39-47

Zhang J, Zhang F, Gariepy T, Mason P, Gillespie D, Talamas E, Haye T (2017) Seasonal parasitism and host specificity of Trissolcus japonicus in northern China. J Pest Sci. doi:10.1007/s10340-0170863-y 